\title{
Comportamento ingestivo diurno de novilhas Jersey sob suplementação com farelo de milho em pastagem de azevém anual
}

\author{
Claiton Baes Moreno ${ }^{1}$, Vivian Fischer ${ }^{2}$, Pedro Lima Monks ${ }^{3}$, Jorge Fainé Gomes ${ }^{4}$, \\ Waldyr Stumpf Junior ${ }^{4}$
}

\author{
1 Pós-graduação em Zootecnia - PPGZ/UFPEL. \\ 2 Departamento de Zootecnia - UFRGS, Professor convidado PPGZ-UFPEL, Bolsista CNPq. Rua Fernandes Vieira 181/601, Porto Alegre - \\ RS, CEP: 90035-091. \\ ${ }^{3}$ Departamento de Zootecnia - UFPEL. \\ ${ }^{4}$ Embrapa CPACT, Pelotas, RS.
}

\begin{abstract}
RESUMO - O objetivo neste trabalho foi observar o comportamento ingestivo diurno de novilhas Jersey em pastejo, submetidas a suplementação com farelo de milho. Foram utilizadas seis novilhas da raça Jersey, com 6 a 9 meses de idade e peso médio de 105,65 \pm 18,2 kg, mantidas em uma pastagem de azevém anual (Lolium multiflorum Lam.), em pastejo contínuo, com lotação variável. Como suplemento, foi fornecido, diariamente às $14 \mathrm{~h}$, farelo de milho na quantidade de $1 \%$ do peso vivo. Os animais foram distribuídos aleatoriamente em um delineamento completamente casualizado em parcelas subdivididas, composto de dois tratamentos (com e sem suplementação de farelo de milho), cada um com três animais, durante quatro períodos experimentais. A avaliação do comportamento ingestivo foi realizada visualmente, registrando-se os tempos gastos pastando, ruminando e descansando entre $7 \mathrm{~h}$ e 18h30. Os animais que não receberam suplemento apresentaram maior tempo de pastejo, porém menor tempo de descanso e menos períodos de pastejo e descanso que os animais sob suplementação. A suplementação influenciou o comportamento ingestivo diurno de novilhas Jersey.
\end{abstract}

Palavras-chave: descanso, pastejo, ruminação

\section{Ingestive diurnal behavior of Jersey heifers supplemented with ground corn on ryegrass pasture}

\begin{abstract}
The trial was conducted to evaluate the effects supplementation with ground corn on grazing dairy heifers diurnal ingestive behavior. Six Jersey heifers, aged of 6 to 9 months and weighing $105.65 \pm 18.2 \mathrm{~kg}$, were used. Heifers were grouped into three animals "testers", and kept in an annual ryegrass (Lolium multiflorum Lam.) pasture, under continuous grazing, with variable stocking rate. Two treatments were used, one as control (no supplement) and another supplemented with ground corn being assigned three animals "testers" for each treatment. Daily, at $14 \mathrm{~h}$, the ground corn was fed at $1 \%$ LW. Animals were randomly assigned to treatments according to a split splot completely randomized design during four experimental periods. Ingestive behavior was evaluated visually and recorded diurnal times spent grazing, ruminating and idling between $7 \mathrm{am}$ and 6:30 pm. Non supplemented animals showed larger grazing time, but shorter idling time, besides fewer grazing and idling periods than supplemented animals. Supplementation affected the diurnal ingestive behavior of Jersey heifers.
\end{abstract}

Key Words: grazing, idling, rumination

\section{Introdução}

Um sistema de produção de bovinos a pasto caracteriza-se por uma complexa e numerosa quantidade de fatores e suas interações, destacando-se a suplementação, que afeta o comportamento ingestivo dos animais e, conseqüentemente, seu desempenho (Karsli, 2001).

O horário de fornecimento (Barton et al., 1992; Adams, 1985; Adams et al., 1986), o tipo de suplemento (Pereira et al., 2005) e sua quantidade (Patiño Pardo et al., 2003) podem influenciar o comportamento ingestivo e o consumo e aproveitamento da pastagem.

As alterações provocadas nos animais poderiam também causar efeitos sobre as características das pastagens, aumentando numericamente as proporções da planta indesejável (Eragrostis plana, Ness) e de material morto (Patiño Pardo et al., 2003).

As atividades diárias do animal em pastejo compreendem períodos alternados de pastejo, descanso e ruminação. O pastejo é a atividade mais importante e a que, em geral, 
demanda maior tempo, de 7 a 10 horas/dia (Hodgson, 1990), além de ser influenciado pelas exigências do animal, pela quantidade e qualidade da pastagem, bem como pela distribuição espacial dos seus componentes botânicos e morfológicos, que, por sua vez, afetam a taxa de ingestão e o tamanho do bocado (Stobbs, 1973; Carvalho, 1997). As condições climáticas também influenciam a distribuição circadiana do tempo de pastejo (Arnold \& Dudzinsky, 1978; Rovira, 1996; Fischer et al., 1998).

Estudos realizados por Hess et al. (1992), Barton et al. (1992), Biscaíno et al. (2001) e Patiño Pardo et al. (2003) demonstram o efeito de substituição, em que o consumo de suplemento reduz a ingestão de pastagem e o tempo de pastejo, embora Restle et al. (1998) não tenham constatado redução do tempo de pastejo.

A ruminação é a segunda atividade em importância, ocorrendo principalmente durante a noite, e corresponde a $75 \%$ do tempo de pastejo, distribuído em períodos médios de 30 minutos (Rovira, 1996). A necessidade de mastigação é relacionada positivamente à quantidade consumida de material indigestível ou pouco digestível e à resistência do material à redução do tamanho de partículas (Welch \& Smith, 1970; Dulphy et al., 1980). A suplementação diminuiu o tempo de ruminação de novilhos em pastagem de azevém (Lolium multiflorum) (Difante et al., 2001).

Este trabalho foi conduzido com o objetivo de avaliar o comportamento ingestivo diurno de novilhas Jersey em pastagem de azevém anual (Lolium multiflorum Lam.), submetidas a dois níveis de suplementação energética.

\section{Material e Métodos}

O experimento foi desenvolvido na Estação Experimental Terras Baixas da EMBRAPA Clima Temperado, situada na região sul do Rio Grande do Sul, no município do Capão do Leão, com 3152'24" de latitude sul e 52 21'24" de longitude oeste, em uma região de planície, a $7 \mathrm{~m}$ acima do nível do mar, na região fisiográfica denominada Encosta do Sudeste (Cassal \& Neutzling, 1970). O município apresenta clima temperado com chuvas bem distribuídas, verões amenos, com temperatura anual média de $17,7^{\circ} \mathrm{C}$, umidade relativa do ar média de $80 \%$ e ocorrência de geadas nos meses de junho, julho e agosto (EMBRAPA, 2002).

O trabalho foi realizado entre os dias 6 de julho e 26 de outubro de 2001 e consistiu de quatro períodos de 28 dias cada: o primeiro de 6 de julho a 2 de agosto; o segundo de 3 a 30 de agosto; o terceiro de 31 de agosto a 27 de setembro; e o quarto de 28 de setembro a 26 de outubro. A temperatura média mensal durante o período experimental foi de
17, $6^{\circ} \mathrm{C}$, com precipitação pluviométrica mensal média de $65 \mathrm{~mm}$ (Tabela 1).

Foram utilizadas seis novilhas puras de origem, da raça Jersey, com idade entre 6 e 9 meses e peso médio de 105,65 $\pm 18,2 \mathrm{~kg}$ ao início do experimento. Os animais receberam medicação antiparasitária antes do início da fase experimental.

Os tratamentos adotados foram com e sem suplementação (controle), sendo destinados três animais "testers" para cada um. O suplemento utilizado foi farelo de milho na quantidade equivalente a $1 \%$ do peso vivo, o qual foi fornecido diariamente às $14 \mathrm{~h}$ em cochos individuais de madeira.

Os três animais destinados à suplementação pesavam, em média, $99 \pm 12,8$ kg e apresentavam escore de condição corporal (ECC) entre 1,5 e 2, considerando uma escala de 1 a 5 (Lowman et al., 1973), e os outros três que não receberam suplemento, $112,3 \pm 15,6 \mathrm{~kg}$ e ECC entre 1,5 e 2, no início do experimento.

As novilhas foram mantidas em uma pastagem de azevém anual (Lolium multiflorum Lam.), com área total de 2 ha, semeada em 21 de abril de 2001, em sistema de pastejo contínuo com carga variável. Destinou-se um piquete para cada grupo, e o manejo da pastagem foi realizado de modo a permitir resíduo mínimo de $1.000 \mathrm{~kg}$ de matéria seca (MS) de forragem e carga animal inicial de $300 \mathrm{~kg}$ de peso vivo/ha para os animais sem suplementação. A oferta inicial de MS foi de $10 \mathrm{~kg}$ MS/100 kg de peso vivo/dia, mantendo-se carga $25 \%$ superior no tratamento com suplementação. A área do piquete destinado ao grupo controle foi de 1,08 ha, enquanto a do grupo de animais suplementados, de $0,92 \mathrm{ha}$.

Foi determinada a quantidade de pastagem de cada piquete no início e final de cada período, pelo método de

Tabela 1 - Valores médios das variáveis meteorológicas relativas ao período experimental

\begin{tabular}{lccccc}
\hline Atributo & \multicolumn{5}{c}{ Período } \\
\cline { 2 - 5 } & 1 & 2 & 3 & 4 & Média \\
\cline { 2 - 5 } & 13,6 & 16,3 & 14,6 & 12,8 & 14,33 \\
$\begin{array}{l}\text { Temperatura mínima } \\
\left({ }^{\circ} \mathrm{C}\right)\end{array}$ & 29,8 & 24,6 & 20,7 & 24,4 & 29,88 \\
$\begin{array}{l}\text { Temperatura máxima } \\
\left({ }^{\circ} \mathrm{C}\right)\end{array}$ & 18,4 & 17,8 & 16,8 & 17,5 & 17,63 \\
$\begin{array}{l}\text { Temperatura média } \\
\left({ }^{\circ} \mathrm{C}\right)\end{array}$ & 78,8 & 87,6 & 83,5 & 82,5 & 83,10 \\
$\begin{array}{l}\text { Umidade relativa do ar } \\
(\%)\end{array}$ & 168 & 159 & 114 & 498 & 234,8 \\
$\begin{array}{l}\text { Fotoperíodo } \\
\text { (horas) }\end{array}$ & & 20 & 0 & 110 & 32,5 \\
$\begin{array}{l}\text { Precipitação pluviométrica } \\
\text { (mm) }\end{array}$ & 0 & & & & \\
\hline
\end{tabular}

Fonte: Embrapa - Estação Agro-climatológica. 
avaliação visual com padrões de 1 a 5 (Haydock \& Shaw, 1975), em que 1 correspondeu à área de menor disponibilidade de forragem e 5 , à de maior disponibilidade. Os cortes destes cinco padrões foram feitos rente ao solo com tesouras de esquilar, utilizando-se um quadrado de $0,25 \mathrm{~m}^{2}$, realizando-se 50 a 55 observações por piquete. As amostras obtidas foram secas em estufa com ventilação forçada a $60^{\circ} \mathrm{C}$ por 48 horas e pesadas, determinando assim a porcentagem de MS do material para os cálculos posteriores.

A taxa de acúmulo de forragem foi calculada utilizando o método de gaiolas de exclusão de pastejo (Gardner, 1986). Colocaram-se três gaiolas em cada piquete e demarcaram-se duas áreas idênticas: uma das áreas foi cortada rente ao chão, usando um círculo de $0,088 \mathrm{~m}^{2}$, onde foi colocada uma gaiola e deixando a outra como ponto de referência para a escolha da nova área para o início do seguinte período. Ao final de cada período, a área demarcada dentro da gaiola foi cortada, pesada verde, seca em estufa a $60^{\circ} \mathrm{C}$ e pesada novamente. A taxa de acúmulo de forragem foi calculada dividindo a quantidade média de MS obtida pelo corte nas gaiolas em dois períodos sucessivos pelo número de dias de cada período experimental.

Foi determinada a proporção de material verde e morto e a composição florística, realizando duas amostragens, no início e na metade de cada período experimental. Foram cortadas entre 35 e 40 subamostras por piquete, por vez, para formar duas amostras compostas, usando um círculo de $0,088 \mathrm{~m}^{2}$. Destinou-se uma amostra para determinação dos componentes vivo e morto e a outra para determinação das espécies, separando-os manualmente, com a amostra ainda fresca. As amostras foram secas em estufa com ventilação forçada a $60^{\circ} \mathrm{C}$ por 48 horas, pesadas e, posteriormente, realizados os cálculos de porcentagem em base seca.

Foi determinada a composição química da pastagem disponível e daquela obtida pela simulação de pastejo (Ruyle \& Dwyer, 1985). As porcentagens de MS, cinzas, matéria orgânica (MO), proteína bruta (PB) foram determinadas segundo métodos constantes em AOAC (1975), e as porcentagens de fibra em detergente neutro (FDN) e fibra em detergente ácido (FDA), segundo métodos descritos em Goering \& Van Soest (1970). A avaliação por meio da simulação do pastejo foi realizada com número variável de amostras colhidas manualmente, durante a atividade de pastejo, próximo aos locais pastejados pelos animais. Em cada período experimental, estas amostras foram coletadas durante dois dias, uma no final da primeira semana e outra no final da terceira semana.

A carga animal foi regulada a cada 14 dias, utilizando-se animais com as mesmas características dos testados, visando manter a disponibilidade de MS constante em cada piquete.

O comportamento animal foi avaliado visualmente por três observadores treinados e os registros, efetuados a cada 10 minutos durante dois dias por período experimental, das 7 às 18h30, totalizando 690 minutos. As atividades comportamentais avaliadas foram os tempos diurnos de pastejo, descanso e ruminação. O número de períodos por dia para cada atividade foi obtido mediante a contagem de sua ocorrência e sua duração média foi determinada dividindo-se a duração diurna da atividade pelo seu número de períodos.

Os animais foram distribuídos em dois grupos homogêneos quanto a peso e idade, e os tratamentos (com e sem suplementação) foram sorteados aleatoriamente aos grupos segundo um delineamento completamente casualizado em parcelas subdivididas, em que o nível de suplementação constituiu as parcelas e os períodos de medida, as subparcelas.

Os atributos do desenvolvimento corporal e do comportamento ingestivo foram submetidos à análise da variância, considerando os efeitos de tratamento e período, utilizando-se o procedimento GLM do SAS (1989), segundo o modelo matemático:

$$
\mathrm{Y}_{\mathrm{ijkl}}=\mathrm{u}+\mathrm{T}_{\mathrm{i}}+\mathrm{A}(\mathrm{T})_{\mathrm{i}(\mathrm{j})}+\mathrm{P}_{\mathrm{k}}+\mathrm{TP}_{\mathrm{jk}}+\mathrm{E}_{\mathrm{ijkl}} \text {, }
$$

em que $\mathrm{u}=$ média geral do experimento; $\mathrm{T}_{\mathrm{i}}=$ efeito de tratamentos $(\mathrm{n}=2) ; \mathrm{AT}_{\mathrm{i}(\mathrm{j})}=$ efeito do animal aninhado dentro do tratamento (erro tipo a); $\mathrm{P}_{\mathrm{k}}=$ efeito dos períodos experimentais $(\mathrm{n}=2) ; \mathrm{TP}_{\mathrm{jk}}=$ efeito da interação tratamento $\times$ período de tempo; $\mathrm{E}_{\mathrm{ijkl}}=$ erro experimental.

A probabilidade mínima para rejeição da hipótese de nulidade foi de 0,05 . As médias foram comparadas pelo teste F, adotando-se o nível de probabilidade máximo de 5\% para rejeição da hipótese de nulidade. Os atributos químicos e produtivos das pastagens em cada período experimental foram submetidos à análise descritiva, obtendo-se suas médias e erros-padrão.

\section{Resultados e Discussão}

Os tempos médios diurnos de pastejo, ruminação e descanso foram, respectivamente, de 376, 130 e 182 minutos. Estes resultados foram um pouco distintos dos observados por Coelho (2006), que verificou tempos médios diurnos de pastejo, ruminação e descanso, respectivamente, de 398, 157 e 92 minutos, trabalhando na mesma área experimental e com novilhas Jersey de peso e idade semelhantes. A marcada diferença entre os tempos de descanso observados entre os dois trabalhos provavelmente decorreu da retirada do tempo de caminhada do tempo de descanso. 
Os animais que não receberam suplemento apresentaram maior tempo de pastejo, mas menores tempo de descanso e número de períodos de pastejo e de descanso em comparação àqueles sob suplementação (Tabela 2). Todavia, não houve diferença quanto ao tempo de ruminação nem quanto ao número de períodos de ruminação entre os animais que receberam suplemento ou não.

Estas diferenças nos tempos de pastejo podem indicar a existência de um efeito substitutivo de grão por pastagem, onde os animais possivelmente consumiram menos pasto e diminuíram o seu tempo de pastejo. Apesar de o consumo não ter sido medido, as outras variáveis medidas indicam esse fato.

O ganho de peso das novilhas controle e sob suplementação não foi diferente (Tabela 2) e o piquete dos animais que receberam suplemento suportou, desde o início, uma carga animal aproximadamente $25 \%$ superior àquela do piquete dos animais sem suplementação. O efeito substitutivo foi encontrado também por Restle et al. (1999) e Minson (1990), que verificaram o decréscimo do tempo de pastejo em animais suplementados. Barton et al. (1992) observaram que novilhos suplementados diminuíram em uma hora e meia o tempo de pastejo em comparação ao grupo controle.

Bailey (1974) também constataram que novilhos da raça Holandesa que receberam $3,6 \mathrm{~kg}$ de aveia reduziram em duas horas o tempo de pastejo. Esse resultado também está de acordo com os obtidos por Biscaino et al. (2001), que compararam o tempo de pastejo diário de novilhos em campo natural, recebendo $0 ; 0,5 ; 1 ; 1,5$ e $2 \%$ de seu peso vivo de farelo de arroz. Esses autores encontraram decréscimo no tempo de pastejo de 530, 380, 395, 332 minutos/dia, respectivamente, para os tratamentos controle, 0,5; 1,5 e $2 \%$, e atribuíram o fato ao efeito substitutivo da suplementação sobre o consumo de campo nativo. No entanto, outros autores não constataram diferenças quanto ao tempo de pastejo. Bremm et al. (2004) não verificaram diferenças quanto ao tempo de pastejo entre novilhas submetidas ou não à suplementação com farelo de trigo.

Silva et al. (2005) forneceram suplemento em níveis crescentes $(0,25 ; 0,5 ; 0,75$ e $1 \%$ do peso vivo) para novilhas mestiças com Holandês, com idade de 12 meses e peso médio de $185 \mathrm{~kg}$, pastejando Brachiaria decumbens. Esses autores não observaram diferenças significativas quanto aos tempos diurnos de pastejo e ruminação entre os animais recebendo os referidos níveis de suplemento.

Patiño Pardo et al. (2003) verificaram efeito quadrático dos níveis de suplementação de sorgo moído (0, 0,75 e $1,5 \%$ do peso vivo), com a diminuição dos tempos de pastejo, ruminação e caminhada dos novilhos que receberam suplemento em relação aos não-suplementados.
Tabela 2 - Valores médios dos tempos gastos em pastejo, ruminação, descanso (minutos), números de períodos de pastejo (NPP), ruminação (NPR) e descanso (NPD) e ganho de peso médio diário de novilhas Jersey em pastagem de azevém anual sob dois níveis de suplementação

\begin{tabular}{|c|c|c|}
\hline \multirow[t]{2}{*}{ Item } & \multicolumn{2}{|c|}{ Suplementação } \\
\hline & Sem & Com \\
\hline Tempo de pastejo (min) & $409,2 \mathrm{a}(59,22)$ & $342,5 b(56,85)$ \\
\hline Tempo de ruminação (min) & $126,6 \mathrm{a}(38,94)$ & $132,9 \mathrm{a}(16,21)$ \\
\hline Tempo de descanso (min) & $154,2 \mathrm{a}(28,99)$ & $210,0 \mathrm{~b}(43,78)$ \\
\hline Períodos de pastejo & $7,6 \mathrm{~b}(1,54)$ & $8,5 \mathrm{a}(1,59)$ \\
\hline Períodos de ruminação & $5,2 \mathrm{a} \quad(1,04)$ & $5,4 \mathrm{a}(0,55)$ \\
\hline Períodos de descanso & $8,2 \mathrm{a} \quad(1,80)$ & $10,3 \mathrm{~b}(2,13)$ \\
\hline Ganho médio diário (kg) & $0,58 \mathrm{a}(0,43)$ & $0,57 \mathrm{a}(0,43)$ \\
\hline Carga animal (kg/ha) & $561(281,54)$ & $685(354,47)$ \\
\hline
\end{tabular}

Médias na linha, seguidas de letras diferentes diferem $(P=0,05)$ pelo teste DMS de Fisher.

Valores dos desvios-padrão nos parênteses.

Pereira et al. (2005) forneceu suplemento a novilhas Jersey em pastagem de azevém anual (Lolium multiflorum) e aveia preta (Avena strigosa, Schreb) com diferentes proporções de milho e farelo de soja na quantidade de $0,75 \%$ do seu peso vivo. Os autores não constataram diferenças quanto aos tempos de pastejo, ruminação e descanso entre os tipos de suplemento.

A ausência de efeito da suplementação sobre o tempo de ruminação, provavelmente, decorreu da pequena ocorrência da atividade durante o período de observação dos animais e da alta qualidade nutricional da pastagem (Tabela 3).

O menor tempo de descanso dos animais controle pode ser explicado pela natureza exclusiva de cada uma destas atividades, isto é, um animal não pode estar engajado em mais de uma atividades ao mesmo tempo, pois gera-se uma competição entre as atividades ingestivas na alocação do tempo pelo animal, como descrito por Fischer et al. (1997, 1998). Por outro lado, os animais sob suplementação receberam, através do consumo do suplemento, uma quantidade de nutrientes de forma rápida e fácil, não exigindo esforço físico e com o mínimo gasto de energia. Dessa forma, os animais que receberam suplemento podem descansar mais. Patiño Pardo et al. (2003) constataram menor tempo de descanso para os animais não-suplementados.

Os períodos de atividade de pastejo e descanso menos freqüentes nos animais controle podem ser explicados pelo seu provável maior consumo de forragem, apresentando, portanto, maior consistência na atividade de pastejo, ou seja, maiores durações de cada período. Contrariamente, Patiño Pardo et al. (2003) verificaram que o número de períodos de pastejo não foi influenciado pela suplementação e constataram média geral de 6,37 ocorrências durante o período diurno. Segundo esses autores, o número de períodos 
Tabela 3 - Valores médios das quantidades de forragem ( $\mathrm{kg}$ de MS/ha) inicial e final, da taxa de crescimento (kg de MS/ha/dia), da produção forrageira total (kg de MS/ha/dia) e da composição química da pastagem em cada período de avaliação

\begin{tabular}{lccccc}
\hline Item & \multicolumn{3}{c}{ Período } & \multicolumn{1}{c}{ Média } \\
\cline { 2 - 4 } & 1 & 2 & 3 & 4 \\
\hline Quantidade inicial & 977,34 & $1.103,34$ & $1.429,33$ & 1.690 & $1.300(322,28)$ \\
Quantidade final & 1.778 & 1778 & $2.372,67$ & 2.410 & $2.084,67(354,44)$ \\
Taxa de crescimento & 28,83 & 24,1 & 33,69 & 25,71 & $2.08(4,20)$ \\
Produção forragem total & $2.585,33$ & $2.552,67$ & 3.316 & 130 & 10,84 \\
\%MM & 14,03 & 13,68 & 12,52 & 14,97 & $12,77(1,44)$ \\
\% PB & 17,55 & 16,06 & 17,32 & $22,48(1,20)$ & $15,9(5,14)$ \\
\% MS & 9,5 & 15,3 & 16,8 & 64,08 & $60,64(5,56)$ \\
\% FDN & 53,36 & 59,33 & 65,77 & 39,87 & $37,56(2,63)$ \\
\% FDA & 33,77 & 38,3 & 38,29 & &
\end{tabular}

Valores dos desvios-padrão nos parênteses.

de descanso foi menor nos animais não-suplementados, o que mais uma vez demonstra sua maior atividade pastoril.

Os períodos de avaliação influenciaram as variáveis comportamentais (Tabela 4). O tempo de pastejo aumentou de 311,7 para 445,8 minutos entre os períodos 1 e 4 . O tempo de pastejo foi negativamente correlacionado à temperatura máxima ( $\mathrm{r}=-0,54 ; \mathrm{P}=0,0065)$, mas positivamente à precipitação $(\mathrm{r}=0,65 ; \mathrm{P}=0,0006)$ e ao fotoperíodo $(\mathrm{r}=0,58 ; \mathrm{P}=0,0027)$. Além disso, o tempo de pastejo foi negativamente relacionado ao teor de $\mathrm{PB}$ do pasto $(\mathrm{r}=-0,65 ; \mathrm{P}=0,0006)$, mas positivamente aos teores de FDN $(r=0,55 ; \mathrm{P}=0,0055)$, FDA $(\mathrm{r}=0,67 ; \mathrm{P}=0,0003)$ e MS ( $\mathrm{r}=0,72 ; \mathrm{P}=0,0001)$, indicando que a redução da qualidade da forragem aumentou no tempo de pastejo dos animais. O número de períodos de pastejo elevou-se do primeiro para o terceiro período experimental (6,8 a 9,7), decrescendo a seguir para 6,9.

Em condições de temperatura moderada, o padrão da atividade de pastejo é predominantemente diurno. Com o aumento da temperatura, os animais passam a exercer a atividade de pastejo durante a noite (Müller, 1989). Segundo Pereira et al. (2005), as altas temperaturas afetaram negativamente o tempo de pastejo diurno, concordando com Forbes (1995) e Patiño Pardo (2003), com relação ao aumento na atividade de pastejo noturno no verão. Segundo Arnold \& Dudzinski (1978), temperaturas próximas a $28^{\circ} \mathrm{C}$ causam estresse e diminuição no tempo diurno de pastejo, aumentando até em $77 \%$ o tempo de descanso neste período do dia. Os valores da RAF nesse período variaram de 0,978 a $0,934 \mathrm{~g} \mathrm{~g}^{-1}$, sendo inferiores aos obtidos por Santos et al. (2004) para o capim-aruana (Panicum maximum Jacq), de 1,490 a 0,275 g g$^{-1}$, e superiores aos valores obtidos por Oliveira et al. (2000) para o capimtifton 85 (Cynodon sp), de 0,59 e 0,27 $\mathrm{g} \mathrm{g}^{-1}$ aos 14 e 70 dias de rebrotação.

Outro fator que pode ter contribuído para o aumento do tempo de pastejo diurno do primeiro ao último período é o incremento verificado nos teores de FDN e FDA, ainda que estes valores não tenham sido muito elevados.

Valores de proteína acima de 8\% (Van Soest, 1994) e de FDN abaixo de 60\% (Noller et al., 1997) não limitariam o consumo dos animais. Os maiores valores de horas de sol, precipitação e temperatura (Tabela 1), além do próprio ciclo de produção da pastagem, contribuíram para os maiores valores de forragem disponível e para a elevação do conteúdo de parede celular (Tabela 3). As modificações das variáveis meteorológicas e da pastagem podem explicar o aumento do tempo de pastejo diurno, pois as temperaturas amenas não forçaram o deslocamento da atividade de pastejo para a noite, mas, em função do acréscimo dos valores percentuais de parede celular, os animais possivelmente despenderam mais tempo na seleção do pasto, deslocando a atividade de ruminação para o período noturno. O aumento do tempo de pastejo deslocou as demais atividades do comportamento ingestivo para a noite, diminuindo a sua duração à medida que os períodos de medida foram realizados, o que explica em parte os resultados da análise de correlação aparentemente contraditórios em relação à literatura, que apontam aumento do tempo de ruminação, conforme se elevou o teor de fibra do pasto, ou do tempo de descanso, à medida que a temperatura média aumentou (Patiño Pardo et al., 2003; Pereira et al., 2005).

O tempo de ruminação diurno também reduziu de 161,7 para 100 minutos e foi positivamente correlacionado à temperatura máxima $(\mathrm{r}=0,67 ; \mathrm{P}=0,0001)$ e ao teor de $\mathrm{PB}$ do pasto ( $\mathrm{r}=054 ; \mathrm{P}=0,0066)$, mas negativamente relacionado à precipitação $(\mathrm{r}=-0,58 ; \mathrm{P}=0,0038)$, ao fotoperíodo $(\mathrm{r}=-0,51 ; \mathrm{P}=0,0105)$, à FDN $(\mathrm{r}=-0,69 ; \mathrm{P}=0,0001)$, FDA $(r=-0,70 ; \mathrm{P}=0,0001)$ e ao teor de MS $(\mathrm{r}=-0,75 ; \mathrm{P}=0,0001)$.

O tempo de descanso diminuiu de 216,7 para 144,2 minutos do primeiro ao quarto eúltimo períodos experimentais. O tempo de descanso foi positivamente relacionado ao teor de $\mathrm{PB}$ do pasto $(\mathrm{r}=0,56 ; \mathrm{P}=00,46)$, mas negativamente à 
Tabela 4 - Valores médios das atividades diurnas de pastejo (minutos), ruminação (minutos) e descanso (minutos), número de períodos de pastejo (NPP), número de períodos de ruminação (NPR), número de períodos de descanso (NPD) dos tratamentos e ganho médio de peso das novilhas Jersey em cada período experimental

\begin{tabular}{|c|c|c|c|c|c|}
\hline \multirow[t]{2}{*}{ Item } & \multirow[t]{2}{*}{ Média } & \multicolumn{4}{|c|}{ Período } \\
\hline & & 1 & 2 & 3 & 4 \\
\hline Tempo de pastejo & $375,72(55,06)$ & $311,7 \mathrm{a}$ & $374,2 b$ & $371,7 b$ & $445,8 c$ \\
\hline Tempo de descanso & $182,10(31,71)$ & $216,7 a$ & $170 \mathrm{c}$ & $197,5 b$ & $144,2 c$ \\
\hline NPP & $8,03(1,42)$ & $6,8 \mathrm{a}$ & $8,7 \mathrm{~b}$ & 9,7b & 6,9a \\
\hline NPR & $5,35(0,74)$ & $6 a$ & $5,7 a$ & $5,4 a$ & $4,3 b$ \\
\hline
\end{tabular}

Médias na linha, seguidas de letras diferentes diferem $(P=0,05)$ pelo teste DMS de Fisher.

precipitação ( $r=-0,50, P=0,0129)$, ao fotoperíodo $(r=-0,44$; $\mathrm{P}=0,0294)$, teor de FDA $(\mathrm{r}=-0,49 ; \mathrm{P}=0,0152)$ e teor de MS $(\mathrm{r}=-0,50 ; \mathrm{P}=0,0130)$.

Houve interação significativa tratamentos $\times$ períodos de medidas. No quarto período, os animais sob suplementação apresentaram tempo de ruminação superior ao dos nãosuplementados, respectivamente, 121,7 e 78,3 minutos, não diferindo nos demais períodos de avaliação. O tempo de ruminação foi positivamente correlacionado à temperatura máxima ( $\mathrm{r}=0,67 ; \mathrm{P}=0,0004)$ e temperatura média $(\mathrm{r}=0,54$; $\mathrm{P}=0,0062)$, mas negativamente à precipitação $(\mathrm{r}=-0,58$; $\mathrm{P}=0,0033)$ e ao fotoperíodo $(\mathrm{r}=-0,51 ; \mathrm{P}=0,0105)$.

\section{Conclusões}

A suplementação com farelo de milho alterou o comportamento ingestivo de novilhas Jersey mantidas em pastagem de azevém anual. A suplementação reduziu a atividade pastoril e aumentou o tempo de ócio dos animais.

\section{Literatura Citada}

ADAMS, D.C.; NELSEN, T.C. et al. Winter grazing activity and forage intake of range cows in the northern great plains. Journal of Animal Science, v.62, n.9, p.1240-1246, 1986.

ADAMS, D.C. Effect of time of supplementation on performance, forage intake and grazing behavior of yearling beef steers grazing Russian wildryegrass in the fall. Journal of Animal Science, v.61, n.4, p.1037-1042, 1985.

ARNOLD, G.W.; DUDZINSKI, M.C. Ethology of free-ranging domestic animals. Amsterdam: Elsevier, 1978. 198p.

ASSOCIATION OF OFFICIAL ANALYTICAL CHEMISTS - AOAC. Official methods of analysis of the association of official analytical chemists. 12.ed. Washington: 1975. 1115p.

BAILEY, P.J. Grazing behavior of steers. Proceedings of the Australian Society of Animal Production, v.10, p.303306, 1974.

BARTON, R.K. ; KRYSL, L.J. ; JUDKINS, M.B. et al. Time of daily supplementation for steers grazing dormant intermediate wheatgrass pasture. Journal of Animal Science, v.70, n.2, p.547-558, 1992.
BISCAINO, G.; GONÇALVES, M.B.F.; FREITAS, F.K. et al. Avaliação do tempo diário total de pastejo de novilhos em campo nativo recebendo diferentes níveis de suplementação. REUNIÃO ANUAL DA SOCIEDADE BRASILEIRA DE ZOOTECNIA, 38., 2001, Piracicaba. Anais... Piracicaba: Sociedade Brasileira de Zootecnia, 2001. (CD-ROM).

BREMM, C.; ROCHA, M.G.; RESTLE, J. et al. Efeito dos níveis e suplementação sobre o comportamento ingestivo de bezerras em pastagem de aveia (Avena strigosa, Schreb.) e azevém (Lolium multiflorum, Lam.). Revista Brasileira de Zootecnia, v.34, n.2, p. 387-397, 2005.

CARVALHO, P.C. A estrutura da pastagem e o comportamento ingestivo de ruminantes em pastejo. In: SIMPÓSIO SOBRE AVALIAÇÃO DE PASTAGENS COM ANIMAIS, 1997, Maringá. Anais... Maringá: Universidade Estadual de Maringá, 1997. p.25-52.

CASSAL, J.L.; NEUTZLING, C.F.M. Desaleitamento precoce usando uma toma de leite na dieta diária de bezerros leiteiros. Pelotas: Universidade Federal de Pelotas, 1970. 3 p.

COELHO, F.J.O. Comportamento ingestivo e desenvolvimento corporal de novilhas Jersey em pastejo. Pelotas: Universidade Federal de Pelotas, 2006. 81p. Dissertação (Mestrado em Zootecnia) - Universidade Federal de Pelotas, 2006.

DIFANTE, G.S.; MARCHEZAN, E.; VILA, S.C.C. et al. Produção de novilhos de corte suplementados em pastagem de azevém submetida a doses de nitrogênio. Revista Brasileira de Zootecnia, v.35, n.4, p.1107-1113, 2006

DULPHY, J.P.; REMOND, B.; THERIEZ, M. Ingestive behavior and related activities in ruminants. In: RUCKECUSH, Y.; THIVEND, P. (Eds.) Digestive physiology and metabolism in ruminants. Wesport: A.V.I. Publication Co, 1980. p.103-122.

EMPRESA AGROPECUÁRIA DE PESQUISA BRASILEIRA EMBRAPA. Boletim agroclimatológico. Pelotas: Estação Agroclimatológica da Embrapa Clima Temperado; Centro de Pesquisas Agropecuárias Clima Temperado, 2002. p.3-8.

FISCHER, V.; DESWYSEN, A.G.; DESPRES, L. et al. Comportamento ingestivo de ovinos recebendo dieta a base de feno durante um período de seis meses. Revista Brasileira de Zootecnia, v.26, p.1032-1038, 1997.

FISCHER, V.; DESWYSEN, A.G.; DESPRES, L. et al. Padrões nictemerais do comportamento ingestivo de ovinos. Revista Brasileira de Zootecnia, v.27, p.362-369, 1988.

FORBES, J.M. Voluntary food intake and diet selection in farms animals. Wallingford: CAB International, 1995. 532p.

GARDNER, A.L. Técnicas de pesquisa em pastagens e aplicabilidade de resultados em sistemas de produção. Brasília: IICA/EMBRAPA-CNPGL, 1986. 197p.

GOERING, H.K.; Van SOEST, P.J. Forage fiber analysis (apparatus, reagents, procedures and some applications). 
Washington, D.C.: U.S. Department of Agriculture: Agriculture Research Service, 1970. 379p.

HAYDOCK, K.P.; SHAW, N.H. The comparative yield method for estimating dry matter yield of pasture. Australian Journal of Experimental Agriculture and Animal Husbandry, v.15, n.76, p.663-670, 1975.

HESS, B.W.; KRYSL, L.J.; JUDKINS, M.B. et al. Supplementation of cattle grazing dormant intermediate wheatgrass pasture. Proceedings of the American Society of Animal Science, v.43, p.43-70, 1992.

HODGSON, J. Grazing management: science into practice. New York: Longman Handbooks in Agriculture, 1990. 203p.

KARSLI, M.A. [2001]. Grazing behavior of ruminant livestock. Disponível em: www.agron.iastate.edu/moore/434/ chapter6htm Acesso em: 4/5/2001.

LOWMAN, B.G.; SCOTT, N.; SOMERVILLE, S. Condition scoring beef cattle. Edinburgh: East of Scotland College of Agriculture, 1973. 8p.

MINSON. D.G. Forage in ruminant nutrition. New York: Academic Press, 1990. 483p.

MÜLLER, P.B. Bioclimatologia aplicada aos animais domésticos. Porto Alegre: Sulina, 1989. 262p.

NOLLER, C.H.; NASCIMENTO, J.D.; QUEIROZ, D.S. et al. Exigências nutricionais de animais em pastejo. In: SIMPÓSIO SOBRE MANEJO DA PASTAGEM, 13., 1997, Piracicaba. Anais... Piracicaba: Fundação de Estudos Agrários Luiz de Queiroz, 1997. p.319-352.

PATIÑO PARDO, R.M.; BALBINOTTI, M.; FISCHER, V. et al. Comportamento ingestivo diurno de novilhos em pastejo submetidos a níveis crescentes de suplementação energética. Revista Brasileira de Zootecnia, v.32, n.6, p.1408-1418, 2003.
PEREIRA, L.M.R.; FISCHER,V.; MORENO, C.B. et al. Comportamento ingestivo diurno de novilhas Jersey em pastejo recebendo diferentes suplementos. Revista Brasileira de Agrociência, v.11, n.4, p.453, 2005.

RESTLE, J.; BACK, M.; BRONDANI, I. et al. Suplementação associada com lasalocida para novilhos em terminação em pastagem cultivada de inverno. Ciência Rural, v.29, n.3, p.555-559, 1999.

RESTLE, J.; POLLI, V.A.; EIFERD, E. et al. Comportamento de novilhos em pastejo horário submetidos a diferentes níveis de suplementação. In: REUNIÃO ANUAL DA SOCIEDADE BRASILEIRA DE ZOOTECNIA, 35., 1998, Botucatu. Anais.. Botucatu: Sociedade Brasileira de Zootecnia, 1998. p.146-151.

ROVIRA, J. Manejo nutritivo de los rodeos de cría en pastoreo. Montevideo: Hemisferio Sur, 1996. 288p.

RUYLE, G.B.; DWYER, D.D. Feedings stations of sheep as an indicator of diminished forage supply. Journal of Animal Science, v.61, n.2, p.349-353, 1985.

STATISTICAL ANALYSIS SYSTEM - SAS. User's guide. Version for WIN-Release 6.11. Cary: 1989. (CD-ROM).

SILVA, R.R.; CARVALHO, G.G.D.; MAGALHÃES, A.F. et al. Comportamento ingestivo de novilhas mestiças de Holandês em pastejo. Archivos de Zootecnia, v.54, n.1, p.63-74, 2005.

STOBBS, T.H. The effect of plant structure on intake of tropical pasture. Difference in sward structure, nutritive value and bite size of animals grazing Setaria anceps and Chloris gayana at various stages of growth. Australian Journal of Agriculture Research, v.24, p.821-829, 1973.

Van SOEST, P.J. Nutritional ecology of the ruminant. Ithaca: Cornell University Press, 1994. 476p.

WELCH, J.G.; SMITH, A.M. Forage quality and rumination time in cattle. Journal of Dairy Science, v.53, p.797-800, 1970. 